AperTO - Archivio Istituzionale Open Access dell'Università di Torino

\title{
Building Narrative Connections among Media Objects in Cultural Heritage Repositories
}

\section{This is the author's manuscript}

Original Citation:

\section{Availability:}

This version is available http://hdl.handle.net/2318/139754

since 2016-11-30T12:53:02Z

Publisher:

Springer International Publishing

Published version:

DOI:10.1007/978-3-319-02756-2_33

Terms of use:

Open Access

Anyone can freely access the full text of works made available as "Open Access". Works made available under a Creative Commons license can be used according to the terms and conditions of said license. Use of all other works requires consent of the right holder (author or publisher) if not exempted from copyright protection by the applicable law. 


\title{
Building narrative connections among media objects in cultural heritage repositories
}

\author{
Antonio Lieto and Rossana Damiano \\ Dipartimento di Informatica, Università degli Studi di Torino \\ Torino, Italy \\ \{lieto, rossana\}@di.unito.it
}

\begin{abstract}
In this paper, we propose a semantic framework for narrativebased access to digital media repositories in the field of cultural heritage. Narrative relations are employed as paths the user can follow to explore a media repository, thus providing a powerful conceptual tool for the description and navigation of resources.
\end{abstract}

Keywords: narrative models, cultural heritage, semantic technologies

\section{Background and Motivations}

When dealing with large and diverse online collections, users need more effective conceptual frameworks to abstract from the complexity of cultural resources. For example, concerning digital imagery, [1] claim that an abstraction layer is needed in the presentation of online archives, since a single investigation may involve different types of artefacts and different realms, such as history, art, archeology, etc. Narrative, in particular, is a powerful metaphor for the exploration of cultural heritage [6], exploited by different projects which range from online access to digital collections $[2,4]$ to situated storytelling on mobile devices [5].

In the last decade, the use of ontologies (and narrative ontologies in particular) in online access to cultural heritage has been investigated by several projects, starting from the pioneering contribution given by the Culture Sampo project [4]. The Agora system [8] provides an event based navigation of cultural objects framing the narrative exploration into historically relevant episodes. In Europeana, it is possible, for example, to navigate among the artifacts representing a given action or displaying a certain character, across a large number or indexed objects; the system does not provide, however, a navigation within or among stories.

In this paper, we describe an application for exploring digital media repositories with the guidance of a set of "cultural archetypes", the Labyrinth system. Inspired by the research in iconology and narratology represented, respectively, by the work of Warburg [9] and Thompson [7], we use the term 'archetype' to refer to a conceptual core, set at the intersection of narrative motifs, iconological themes and classical mythology. For example, the archetype of the "labyrinth" can be employed to track the connection between a Greek vase representing 


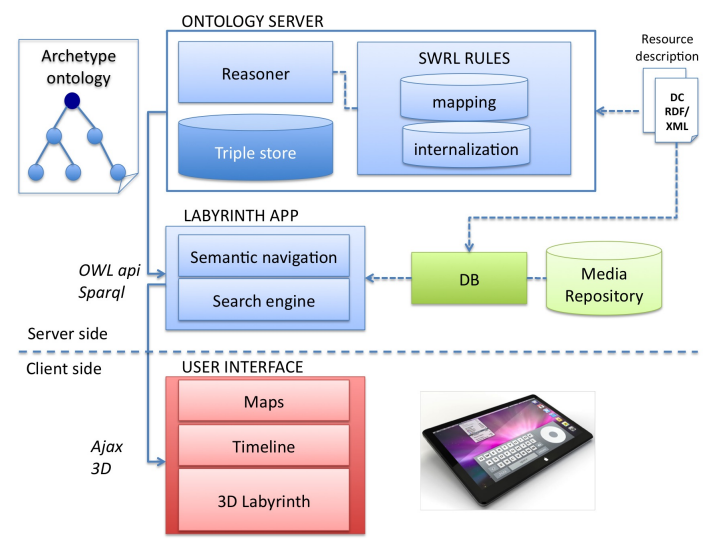

Fig. 1. The architecture of the system

Theseus and the playbill of a theatrical play inspired by the story of Ariadne, since both involve a character who plays some part in the classical myth. The system relies an OWL ontology, the Archtype Ontology, where each archetype is described by the set of its related stories, characters, locations and objects (a description can be found in [3]).

\section{System Architecture}

The Labyrinth system allows the user to explore a repository of media resources through the conceptual mediation of an "archetype" of narrative nature. The system encompasses four main modules (see Fig. 1):

- The Ontology Server maintains Archetype Ontology, maps the media resources onto the ontology (through a SWRL rule base), and provides the reasoning services to the web application. ${ }^{1}$

- The Media Repository is indexed by a relational database (a mySql DB).

- The Web application, written in Java, provides search and navigation by querying the Ontology Server through SPARQL language.

- The web site supports the interaction with the user through maps, timelines and 3D navigation.

When a new resource is added to the database, the information about it (i.e., its metadata) is integrated into the ontology as well. First, the internalization phase imports the metadata of the resource (creator, date, etc) into the ontology. Then, the mapping of the imported resource with the archetypes (and narrative features in particular) is performed on the internalized metadata. Both steps are achieved via rules encoded in SWRL format, in order to guarantee the portability of the system.

\footnotetext{
${ }^{1}$ Currently, the ontology server is provided by the Owlim RDF database management
} systems (www.ontotext.com/owlim), Standard Edition. 


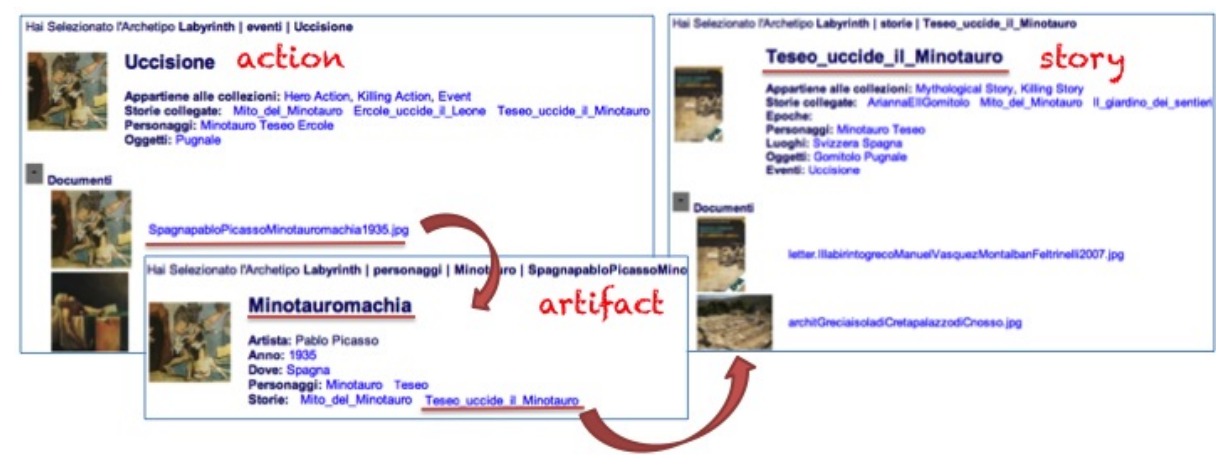

Fig. 2. A navigation path in the Labyrinth system (in Italian). The first step, "action" (top left) shows information about the "killing" action ("Uccisione"), the stories it belongs to, the characters who take part in it, the artworks depicting it; the second step, "artifact" (bottom), shows the information about an artwork, its creator, the characters it displays, the stories it refers to, etc.; the third step, "story" (top right), shows the information about a story ("Theseus kills the Minotaur", "Teseo uccide il Minotauro").

\section{Narrative navigation}

After selecting an archetype, the system allows the user to choose one of its defining element (i.e., the stories, characters, events, locations, etc. related with the selected archetype) and filters the media resources in the repository according to their relation with chosen element. When the user selects one of the proposed resources, she/he starts navigating the repository resource by resource, following the relations between them.

As an example of the user-system interaction, let us assume that the user selects the "Labyrinth" archetype, and then chooses to explore the actions related with it. The system shows a set of action types, displaying, for each of them, the number of related artifacts. If the user chooses the "killing" action, the system will display the screenshot in Fig. 2 (top left, "action"), which includes the following information:

- the action categories it belongs to in the ontology: here, the "Hero action" and the "Killing action".

- the stories to which the action belongs, which include both single episodes ("Theseus kills the Minotaur") and larger stories ("Theseus and the Minotaur"). Notice that the latter information is not explicitly stated in the ontology, but has been added by reasoner as an effect of the inferences conducted on the partOf relations among stories.

- the characters and objects that play some role in the different occurrences of the action: "Theseus", "Minotaur", "Heracles" for the characters, and "dagger" for the objects. 
In the bottom part of the page, the user can browse the artworks related with the "killing" action. If the user clicks on the first artwork (Picasso's painting "Minotauromachia", Fig. 2, bottom), the system displays the information about the artwork, including the characters it involves ("Theseus" and the "Minotaur") and the story it refers to (again, "Theseus and the Minotaur" and the episode "Theseus kills the Minotaur" in particular). If user decides to continue the navigation from this artifact to one of its related stories (let assume the user chooses the episode "Theseus kills the Minotaur") the system displays (see Fig. 2, top right, "story") the information about the selected story.

\section{Conclusions and Future Work}

The system described in this paper relies on an ontology to let the user explore the relations among a set of media resources which share common narrative features, such as characters, actions, objects, locations.

A prototype of the systems was developed and tested on a pilot corpus of 24 resources of different type and format. The corpus was issued from a bibliographical search conducted by editorial professionals and included 8 visual artworks, 6 literary works, 2 movies and 2 musical works. A test on a larger corpus is planned as future work.

\section{References}

1. C.-c. Chen, H. D. Wactlar, J. Z. Wang, and K. Kiernan. Digital imagery for significant cultural and historical materials. International Journal on Digital Libraries, $5(4): 275-286,2005$.

2. T. Collins, P. Mulholland, and Z. Zdrahal. Semantic browsing of digital collections. In The Semantic Web-ISWC 2005, pages 127-141. Springer, 2005.

3. R. Damiano and A. Lieto. Ontological Representations of Narratives: a Case Study on Stories and Actions. In 2013 Workshop on Computational Models of Narrative, volume 32 of (OASIcs), pages 76-93, Dagstuhl, Germany, 2013.

4. E. Hyvönen, E. Mäkelä, T. Kauppinen, O. Alm, J. Kurki, T. Ruotsalo, K. Seppälä, J. Takala, K. Puputti, H. Kuittinen, et al. Culturesampo: A national publication system of cultural heritage on the semantic web 2.0. The Semantic Web: Research and Applications, pages 851-856, 2009.

5. V. Lombardo and R. Damiano. Storytelling on mobile devices for cultural heritage. New Review of Hypermedia and Multimedia, 18(1-2):11-35, 2012.

6. P. Mulholland and T. Collins. Using digital narratives to support the collaborative learning and exploration of cultural heritage. In Database and Expert Systems Applications, 2002. Proceedings. 13th International Workshop on, pages 527-531. IEEE, 2002.

7. S. Thompson. Myths and folktales. The Journal of American Folklore, 68(270):482488, 1955.

8. C. van den Akker, M. van Erp, L. Aroyo, R. Segers, L. Van der Meij, S. Lgene, and S. G. Understanding objects in online museum collections by means of narratives. In Proc. of the Third Workshop on Computational Models of Narrative (CMN12).

9. A. Warburg. Der Bilderatlas Mnemosyne, volume 1. Akademie Verlag, 2008. 